\section{CAD-FEA modeling and fracture resistance of bilayer zirconia crowns manufactured by the rapid layer technology}

\author{
Julia Magalhães Costa Lima (101, Anna Karina Figueiredo Costa (이,

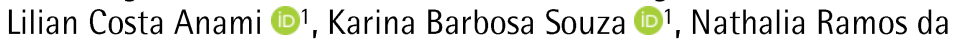 \\ Silva $\mathbb{1}^{2}$, Renata Marques de Melo Marinho (ㄴ)1, Alexandre Luis \\ Souto Borges (1)1, Marco Antonio Bottino (ib1, Mutlu Özcan (1) 3, \\ Rodrigo Othávio Assunção Souza (1)?
}

In the RLT (Rapid Layer Technology), veneering ceramic and framework are fabricated by computer-aided design/computer-aided manufacturing (CAD/CAM) and then cemented to obtain the restoration. This study aimed to evaluate the effect of the thickness of veneering ceramic manufactured by the RLT technique on the fracture resistance (FR) of bilayer crowns with zirconia frameworks. Twenty zirconia frameworks and twenty feldspathic posterior crowns with two different veneering ceramic occlusal thicknesses $(1 \mathrm{~mm}=\mathrm{TF} 1 ; 2 \mathrm{~mm}=\mathrm{TF} 2)$ were manufactured using CAD/CAM system. The specimens were luted to an epoxy resin abutment with resin cement and mechanically cycled $\left(200 \mathrm{~N}\right.$ and $4.5 \times 10^{5} \mathrm{~Pa}, 37^{\circ} \mathrm{C}, 2 \times 10^{6}$ cycles, $\left.3 \mathrm{~Hz}\right)$. The FR test was performed $(10 \mathrm{kN}, 0.5 \mathrm{~mm} / \mathrm{min})$, and the specimens were analyzed in a stereomicroscope. For the stress analysis (finite element analysis, FEA), a $10 \mathrm{kN}$ load was equal to the in vitro test, and the principal stress was evaluated. The FR data were analyzed by Student's t-test and Weibull's analysis. The thickness influenced the FR of bilayer crowns. The FR was higher in the TF2 than in the TF1 group. The TF2 group presented the highest characteristic strength compared to the group TF1. The predominant type of failure was delamination. The FEA showed higher stress concentrations below the loading application point at the veneering cement interface in the 1$\mathrm{mm}$-thick model. The bilayer crowns manufactured using the approach of $2 \mathrm{~mm}$ of veneering ceramic promoted higher FR compared to the group with $1 \mathrm{~mm}$ veneering ceramic. Also, the FEA showed that the veneer ceramic thickness has an effect on stress distribution in zirconia-based bilayer crowns.
1 Department of Dental Materials and Prosthodontics, Institute of Science and Technology (ICT), São Paulo State University (UNESP/FOSJC), São José dos Campos, SP, Brazil.

2 Department of Dentistry, Division of Prosthodontics, Federal University of Rio Grande do Norte, Natal, RN, Brazil.

3 Dental Materials Unit, Center for Dental and Oral Medicine, Clinic for Fixed and Removable Prosthodontics and Dental Materials Science, University of Zurich, Zurich, Switzerland.

Correspondence: Correspondence: Rodrigo 0. A. Souza; Federal University of Rio Grande do Norte (UFRN), Department of Dentistry, Av. Salgado Filho, 1787, Lagoa Nova, Natal / RN. CEP: 59056-000. Tel: +55(84)3215-4104. e-mail:rodrigoothavio@gmail.com

Key Words: zirconia, porcelain, ceramic, finite element analysis.

\title{
Introduction
}

The evolution of computer-aided design/computer-aided manufacturing (CAD/CAM) technology have greatly promoted advances to the oral rehabilitation, in this way enabling and ensuring a faster workflow (1). Also, the manufacturing of indirect restorations from ceramic blocks and or discs that display less internal defects (flaws) may improve the mechanical strength of the restoration itself (2). $\mathrm{CAD} / \mathrm{CAM}$ systems are able to manufacture several types of indirect ceramic restorations, ranging from delicate and smaller partial restorations such as ultra-thin ceramic veneers (3) to full coverage restorations such as crowns, which can be manufactured either as bilayer (with a framework and veneering ceramic) or monolithic (single structure) (4).

Bilayer ceramic crowns were the first metal-free crown option to be introduced in the oral rehabilitation as well as they have been widely studied in the literature (5). One of the advantages of the bilayer crowns is their capacity to mask dark substrates when comparing to the monolithic crowns (6). Previous clinical studies in which the performance of bilayer ceramic crowns were evaluated have estimated a survival rate ranging from $67.2 \%$ after 10 years (7) to $97.73 \%$ after 5 years (8). The delamination and chipping of veneering ceramic crowns are the major cause of failure of this type of restoration (6-8). Nonetheless, this issue can be related to several factors, such as the shape and thickness of the veneering ceramic and framework $(9,10)$, ceramics application techniques $(11)$, and the residual thermal stress (12).

Among these factors, the residual thermal stress is caused by the incompatibility between the coefficients of thermal expansion of the veneering ceramic and the framework (13), as well as by the presence of thermal gradients on the veneering ceramic originated during the cooling after the firing steps (14) which is performed in the conventional techniques (hand-layering and pressing). The use of 
CAD/CAM technology to manufacture veneering ceramic crowns have been proposed to prevent residual thermal stress accumulation (15). Out of the CAD/CAM techniques, one may point out the Rapid Layer Technology (RLT) preparation technique, in which the zirconia frameworks and veneering ceramics can be prepared from a single scan of the preparation.

In this technique, the manufacturing process of restoration begins with a scan of the clinical situation of the patient utilizing a three-dimensional scanner. Furthermore, the CAD equipment draws the framework and the veneering ceramic with the anatomical shape of the final prosthetic restoration of the patient, and subsequently mills the framework and the veneering ceramic from prefabricated blocks of specific materials. Afterwards, the veneering ceramic is cemented to the framework and the final restoration is thus obtained. Previous studies have reported promising results regarding the mechanical properties and stability of crowns using veneering ceramic manufactured by RLT technique (15-17).

The residual thermal stress is also influenced by the thickness of the veneering ceramic because the thickness appeared to be associated with the residual stress accumulated during the cooling step (18). Hence, increasing the thickness of the veneering ceramic can slow down the cooling rate internally, generating non-uniform temperature gradients across the ceramic material and, thus, reducing the fracture resistance of the restoration (9). Previous studies have reported that bilayer samples and crowns with greater thickness of the veneering ceramic, as well as with lower framework and or veneer thickness ratio, have presented lower rates of mechanical strength $(10,19,20)$.

Consequently, taking into consideration the limited information regarding the RLT technique and the variation of thickness of veneering ceramic, this study aimed to evaluate the effect of the veneering ceramic thickness manufactured by the RLT technique on the fracture resistance of mechanically aged bilayer crowns with zirconia frameworks.

\section{Material and methods}

Table 1 shows details on the brand, manufacturers, chemical composition, and batch number of the materials utilized in this study.

Table 1. Commercial name, manufacturers, chemical composition, and batch number of materials used in this study.

\begin{tabular}{|c|c|c|c|}
\hline Material & Product name & Manufacturers & Lot. \\
\hline Epoxy resin & Resina G10 (EpoxyglasTM) & $\begin{array}{l}\text { International Paper, } \\
\text { Hampton/SC, EUA }\end{array}$ & - \\
\hline $\begin{array}{l}3 \text { mol\% yttria stabilized tetragonal } \\
\text { zirconia polycrystal (3Y-TZP) blocks }\end{array}$ & Vita In-Ceram YZ & $\begin{array}{l}\text { Vita Zahnfabrik, Bad } \\
\text { Säckingen, Alemanha }\end{array}$ & 23611 \\
\hline $\begin{array}{l}\text { coloring liquid for zirconia } \\
\text { framework }\end{array}$ & $\begin{array}{c}\text { Vita In-Ceram YZ Coloring Liquid, } \\
\text { Light }\end{array}$ & $\begin{array}{l}\text { Vita Zahnfabrik, Bad } \\
\text { Säckingen, Alemanha }\end{array}$ & 35130 \\
\hline Veneering ceramic & $\begin{array}{c}\text { VITABLOCS TriLuxe Forte TF-14, Vita } \\
\text { Zahnfabrik }\end{array}$ & $\begin{array}{l}\text { Vita Zahnfabrik, Bad } \\
\text { Säckingen, Alemanha }\end{array}$ & - \\
\hline Glaze & Vita Akzent & $\begin{array}{l}\text { Vita Zahnfabrik, Bad } \\
\text { Säckingen, Alemanha }\end{array}$ & 22601 \\
\hline Aluminum oxide & - & $\begin{array}{l}\text { Asfer Chemical Ltda, São } \\
\text { Caetano do Sul, Brazil }\end{array}$ & - \\
\hline Hydrofluoric acid gel 5\% & - & $\begin{array}{l}\text { Formula and Action, São Paulo, } \\
\text { Brazil }\end{array}$ & - \\
\hline Silane & $\begin{array}{l}\text { Clearfil SE Bond Primer and Clearfil } \\
\text { Porcelain Bond Activator }\end{array}$ & $\begin{array}{l}\text { Kuraray Noritake Dental, } \\
\text { Tóquio,Japão }\end{array}$ & 051505/ 0270AA \\
\hline Dual-resin cement & Panavia F & $\begin{array}{l}\text { Kuraray Noritake Dental, } \\
\text { Tóquio,Japão }\end{array}$ & 051220 \\
\hline
\end{tabular}

\section{Anatomical preparations $(\mathbf{G 1 0})$}

To simulate an anatomical preparation corresponding to the human first mandibular molar, a drawing was performed ( $6 \mathrm{~mm}$ height; end chamfered $1.2 \mathrm{~mm}$ ) in a 3D modeling program (Rhinoceros 4.0, Seattle, WA, USA). Afterwards, the 3D design modeling data was sent to a milling unit (Zenotech mini milling machine, Wieland Dental + Technik GmbH \& Co. KG), and 20 preparations were designed from raw materials such as epoxy resin reinforced by glass fiber (NEMA grade G-10, International Paper, Hampton, VA, USA), which has mechanical properties similar to those of dentin (21). 


\section{Zirconia frameworks preparations}

A G10 preparation was scanned by a digital inEos Blue scanner (Sirona Dental Systems, Bensheim, Germany) connected with the 3.88 InLab software (Sirona Dental Systems) utilized to generate a threedimensional image of the framework. Posteriorly, pre-sintered blocks of tetragonal-zirconia partially stabilized by yttrium oxide (3Y-TZP, Vita In-Ceram YZ, Vita Zahnfabrik, Bad Säckingen, Germany) were milled (CEREC MC XL InLab, Sirona Dental Systems) to obtain 20 identical zirconia frameworks with 1$\mathrm{mm}$-thick occlusal surfaces. The frameworks were immersed in coloring liquid (LL1, Vita Zahnfabrik) for 2 minutes and sintered following the recommendations of the manufacturer (VITA T ZYrcomat, Vita Zahnfabrik).

\section{Obtaining the veneering ceramics}

One sintered-zirconia framework was placed on the $\mathrm{G} 10$ anatomical preparation, and a new scan was performed to obtain the drawing of the veneering ceramics. The veneering ceramics (VITABLOCS TriLuxe Forte TF-14, Vita Zahnfabrik) were milled (CEREC MC XL InLab, Sirona Dental Systems) according to the two levels of thicknesses utilized in this study (veneering ceramics thickness):

$1 \mathrm{~mm}$ thickness on the major groove of the occlusal surface (TF1 group; $n=10$ );

$2 \mathrm{~mm}$ thickness on the major groove of the occlusal surface (TF2 group; $\mathrm{n}=10$ ).

A layer of glaze (Vita Akzent, Vita Zahnfabrik) was applied and sintered over all the veneering ceramic according to the recommendations of the manufacturers (Vita VACUMAT 6000MP, Vita Zahnfabrik).

\section{Cementing the veneering ceramics to the zirconia frameworks}

The external surfaces of zirconia frameworks were sandblasted with $50-\mu \mathrm{m}$ aluminum oxide (Asfer Chemical Ltda, São Caetano do Sul, Brazil) with a pressure of $2.5 \times 10^{5} \mathrm{~Pa}, 15 \mathrm{~mm}$ of distance, and for 10 seconds. The inner surfaces of the ceramics were etched using 5\% hydrofluoric acid gel (5\% Formula and Action, São Paulo, Brazil) for 60 seconds and afterwards rinsed with water and dried out with air jets. Subsequently, the silane coupling agent (Clearfil SE Bond Primer and Porcelain Bond Activator Clearfil, Kuraray Noritake Dental, Tokyo, Japan) was applied using a microbrush to the etched surfaces and let it to evaporate for 60 seconds. The paste A and B of the dual-resin cement Panavia F (Kuraray Noritake Dental) were mixed and applied to the inner surface of the veneering ceramic according to the instructions of the manufacturers. Following next, this ceramic was smoothly pressed over the zirconia framework with uniform and constant pressure. Excess cement was removed before the final setting, and each side of the crown was light-cured for 40 seconds $\left(1200 \mathrm{~mW} / \mathrm{cm}^{2}\right.$, Radii-Cal, SDI Limited, Victoria, Australia).

Cementing the crowns to the $\mathbf{G} 10$ anatomical preparations

The G10 anatomical preparations were etched with 5\% hydrofluoric acid gel for 60 seconds, and afterwards washed with a spray of air and or water for 30 seconds. The silane agent (Clearfil SE Bond Primer and Clearfil Porcelain Bond Activator, Kuraray Noritake Dental) was applied and let it evaporate, following the application of ED Primer (Kuraray Noritake Dental) to the anatomical preparations. Next, the resin cement (Panavia F, Kuraray Noritake Dental) was applied to the inner surfaces of the zirconia frameworks, and the crown was placed with light-hand pressure on the $\mathrm{G} 10$ anatomical preparation. Then, a 750 grams load was applied over the restoration itself. After the removal of excess cement, the preparation was light-cured during 40 seconds on each side of the crown. Finally, the samples were immersed in distilled water and stored in a bacteriological oven (Orion 502, Fanem, São Paulo, Brazil) at temperature of $37^{\circ} \mathrm{C}$ over a period of 24 hours.

\section{Mechanical cycling}

All the samples (20 crowns) were mechanically cycled (11000 Erios, Erios Technical and Scientific Equipment Ltd., São Paulo, Brazil) with a maximum load of $200 \mathrm{~N}$ (pressure $4.5 \times 10^{5} \mathrm{~Pa}$ ) in distilled water at $37^{\circ} \mathrm{C}$ utilizing a stainless steel piston with a ballpoint of $6 \mathrm{~mm}$ diameter, for $2 \times 10^{6}$ cycles, and at a frequency of $3 \mathrm{~Hz}$. Every crown was checked for any sort of damage before and after the mechanical cycling. 


\section{Fracture resistance}

All samples were tested for fracture resistance. In this procedure, each sample was fixed on the testing machine (EMIC DL 1000, São José dos Pinhais, Brazil) with the help of the load applicator tip (a ballpoint of $6 \mathrm{~mm}$ diameter) pointed at the center of the major groove on the occlusal surface. The compression test was conducted with a load cell of $10 \mathrm{kN}(0.5 \mathrm{~mm} / \mathrm{min})$ and was stopped at the first sign of fracture using the sound technique together with changes in the graphic presentation of the loaddisplacement curve (9).

\section{Failure mode analysis and Fractography}

The failures of the crowns were evaluated with the aid of a stereomicroscope (70x, Discovery V20, Zeiss, Germany), and were classified as following: crack, chipping, delamination, and catastrophic. Also, the extent of failures was checked and classified according to Burke's classification (22). The fragments of representative specimens were analyzed for better visualization of the fractography characteristics and to determine the origin of the failure using a Scanning Electron Microscopy (SEM) (Inspect S50, FEI Company, Brno, Czech Republic) (21).

\section{Finite element analysis (FEA)}

Two specimens ( $\mathrm{G} 10$ preparation, resin cement, framework, and veneering ceramics) were modeled with Rhinoceros software (version 4.0 SR8, McNeel North America, Seattle, WA, USA) to simulate the different thicknesses of veneering ceramics in the conditions described previously. The interface resin cement-/G10 was suppressed because their thin layer would increase the number of elements without promoting different results. Both models were imported as files into Ansys software (ANSYS 13.0, ANSYS Inc., Houston, Texas, USA). All materials were considered homogenous, linearly elastic, and isotropic for the structural mechanical analysis. The mechanical properties assigned to these materials are summarized in Table 2.

Table 2. Mechanical properties of the materials: modulus of elasticity (in GPa) and Poisson's ratio, according to published data.

\begin{tabular}{lcc}
\multicolumn{1}{c}{ Material } & Elastic modulus & Poisson's ratio \\
\hline $\mathrm{G} 10$ & 14.9 & $0.31(17)$ \\
Resin cement (Panavia F) & 9.2 & $0.28(18)$ \\
Y-TZP In-Ceram YZ (Vita Zahnfabrik) & 209.3 & $0.32(19)$ \\
Triluxe Forte (Vita Zahnfabrik) & 70.7 & 0.21 \\
\hline
\end{tabular}

aData for Triluxe Forte ceramic were obtained for Sonelastic equipment (ATCP, Engenharia Física, São Carlos, SP, Brazil)

The geometric contacts were considered perfectly bonded. The mesh had a slow-transition among the geometries and the element used was 10-node tetrahedral, with the element size was $0.3 \mathrm{~mm}$ for all models except the base that was optimized nearby the interface with $\mathrm{G} 10$ where applied 50\% of relevance for $\mathrm{G} 10$. Movements of the base were constrained in all directions, and a $10 \mathrm{kN}$ load was applied in the center of the crowns, distributed equally in three points as shown in the compressed area in Figure 1. A linear static structural analysis was performed for observation of the stress distribution in the frameworks, veneering ceramics, and resin cement layers. The von Mises stresses criteria were used for observation of the coherence of the results. The maximum principal stresses (MPS) criteria were used for the analysis of the tensile stress concentration since the materials studied exhibited brittle behavior. 


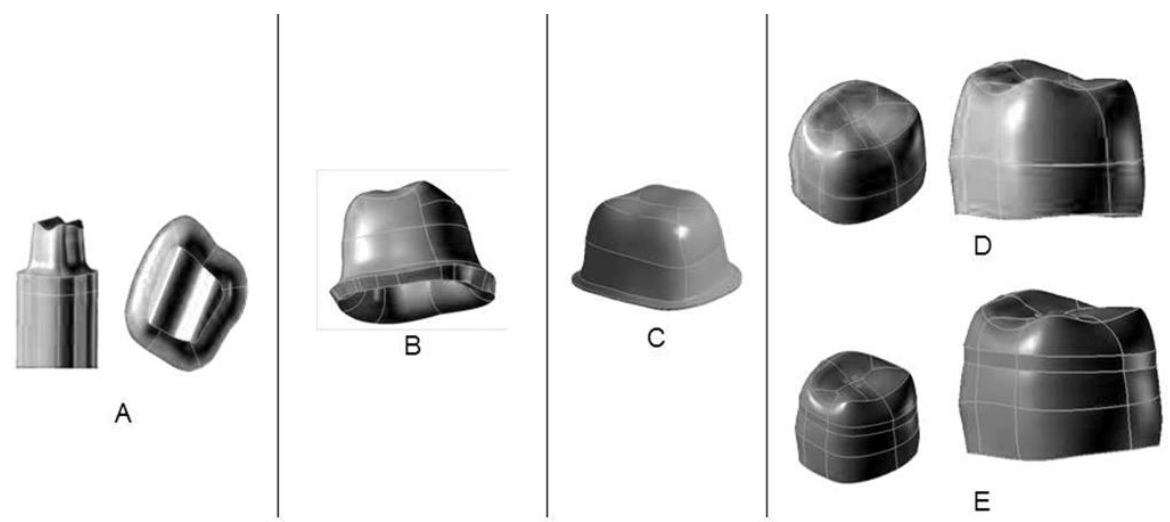

Figure 1. The geometry of components of two tested models. (A) The geometry of the preparation in G10. (B) Design of the Y-TZP framework. (C) Cement layer between the crown and the framework. (D) Veneer crown with 1-mm-thick coating. (E) Veneer crown with 2mm-thick coating

Prior to the statistical analyses, the distribution of the data obtained on fracture resistance test was assessed by the Shapiro-Wilk's test and homogeneity by the Levene's test. The results indicated normal distribution and equality of variances ( $p>0.05$ ). The "Open Source Epidemiologic Statistics for Public Health" website (www.openepi.com) was used to calculate the sample power of the study. The maximum force of fracture resistance $(\mathrm{N})$ data was subjected to the Student's t-test $(\mathrm{p}<0.05)$. The program STATISTIX (Analytical Software Inc., version 8.0, 2003) was used to performed the statistical analysis (level of significance of $5 \%)$.

Additionally, to evaluate the reliability of the results obtained, the Weibull analysis was performed using the Weibull modulus $(\mathrm{m})$, the characteristic strength $\left(\sigma_{0}\right)$, under confidence interval of $95 \%$. The Weibull analysis was performed using the Minitab Software (v.17, 2013, State College, PA, USA).

\section{Results}

The power of sample rate was $99.98 \%$. Any of the groups have showed pre-test failure, as there were no signs of cracking and or chipping before and after the mechanical cycling.

\section{Fracture resistance}

The results on the fracture resistance tests are showed in Table 3. The Student's t-test have showed that the fracture resistance of the 2-mm-thick group (TF2: $2069.46 \pm 324.99 \mathrm{~N}$ ) was significantly higher than the 1-mm-thick group (TF1: $1391.78 \pm 318.50 \mathrm{~N})(p=0.0001)$.

The Weibull modulus $(\mathrm{m})$ was not statistically different between the two groups $(p=0.574)$. However, there was a statistically difference noticed for the characteristic strength $\left(\sigma_{0}\right)(p=0.000)$. The TF2 group presented the highest characteristic strength (2201.56 N) when compared to the group TF1 $(1464.32 \mathrm{~N})$. The Weibull distributions are graphically presented in Figure 2 and its associated parameters are summarized in Table 3.

Table 3. Fracture strength $(\mathrm{N})$, Characteristic strength $\left(\sigma_{0}\right)$, Weibull modulus $(\mathrm{m})$ and $95 \% \mathrm{Cl}$ for shear bond strength according experimental groups.

\begin{tabular}{cccccc} 
Group Name & $\begin{array}{c}\text { Fracture strength } \\
(\mathrm{N})\end{array}$ & $\begin{array}{c}\text { Weibull } \\
\text { Modulus }(\mathrm{m})\end{array}$ & $95 \% \mathrm{Cl}$ for $m$ & $\begin{array}{c}\text { Weibull } \\
\text { Characteristic } \\
\text { strength }\left(\sigma_{0}\right)(\mathrm{MPa})\end{array}$ & $\begin{array}{c}95 \% \mathrm{Cl} \text { for }\left(\sigma_{0}\right) \\
(\mathrm{MPa})\end{array}$ \\
\hline TF1 & $1391.78 \pm 318.50^{\mathrm{B}}$ & $8.56^{\mathrm{a}}$ & $6.26 \pm 11.71$ & $1464.32^{\alpha}$ & $1351.52 \pm 1586.54$ \\
TF2 & $2069.46 \pm 324.99^{\mathrm{A}}$ & $7.11^{\mathrm{a}}$ & $4.05 \pm 12.50$ & $2201.56^{\beta}$ & $2008.75 \pm 2412.86$
\end{tabular}

\footnotetext{
${ }^{*}$ Equal uppercase letters indicate statistical similarity among results of fracture strength and Weibull modulus. Equal lower-case letters indicate statistical similarity among Weibull modulus. Equal greek alphabet letters indicate statistical similarity among Weibull characteristic strength
} 
Figure 2. Weibull curves $(95 \% \mathrm{Cl})$ showing the cumulative probability of failures of the different surface treatments tested. $\mathrm{m}=$ Weibull modulus, $\sigma_{0}=$ characteristic strength, Corr $=$ correction.

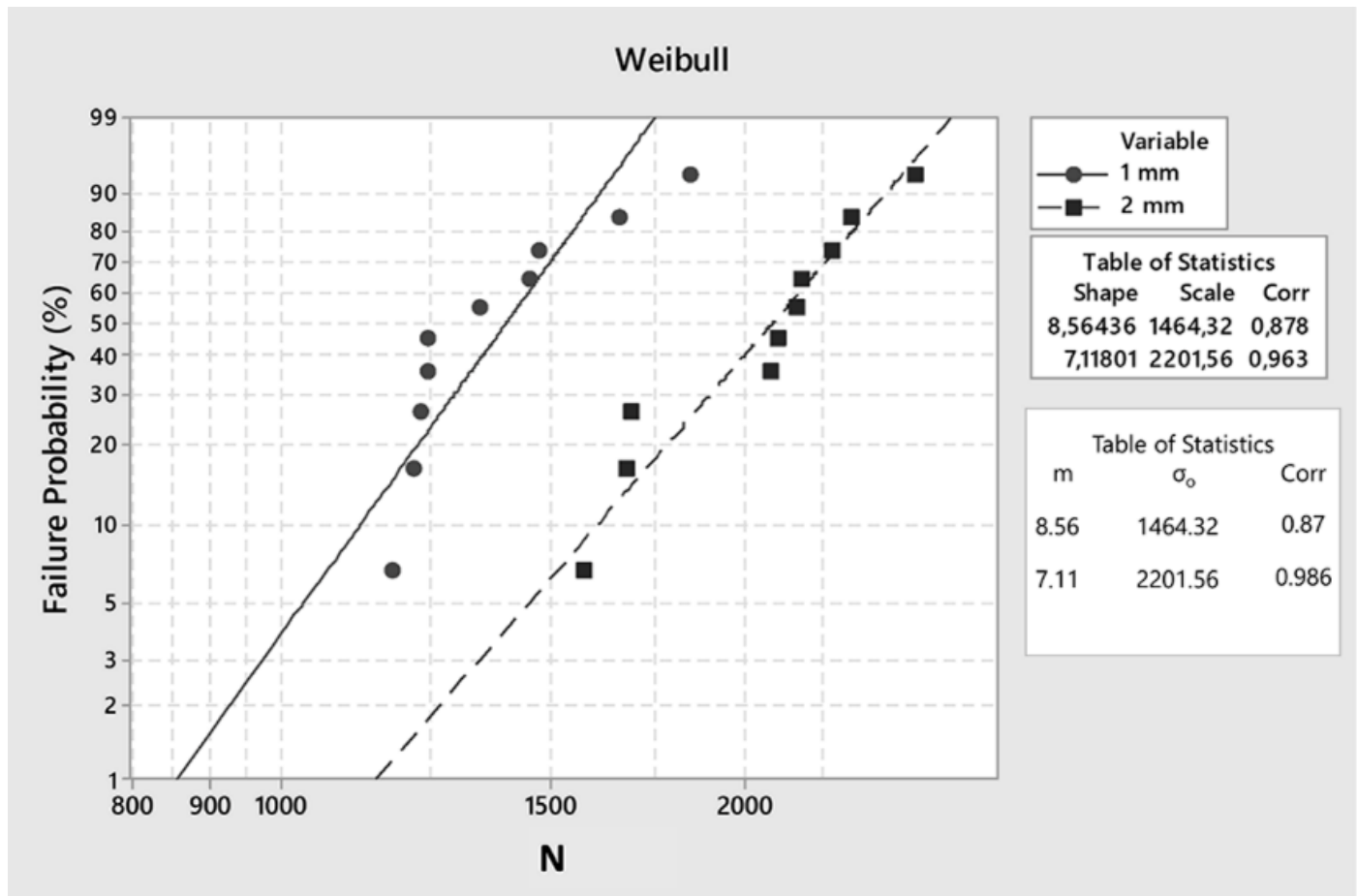

\section{Failure analysis and Fractography}

The predominant failure mode between the two groups was delamination. According to Burke's classification, type II was the most prevalent for both groups. In addition, the TF1 group did not show any type III failure, while $20 \%$ of the samples in the TF2 group showed this sort of failure (Table 4). The fractures have originated on the occlusal site below the point of load application where the subsurface damage was observed (Figure 3).

Table 4. Failure modes for experimental groups.

\begin{tabular}{|c|c|c|c|c|c|}
\hline \multirow{3}{*}{ Groups } & Cracking/ Chippinga & \multicolumn{3}{|c|}{ Delamination ${ }^{\mathrm{a}}$} & Catastrophic failure \\
\hline & \multicolumn{5}{|c|}{ Burke's classification $^{b}$} \\
\hline & Type I & Type II & Type III & Type IV & Type V \\
\hline TF1 & 0 & $5(50 \%)$ & 0 & $3(30 \%)$ & $2(20 \%)$ \\
\hline TF2 & 0 & $4(40 \%)$ & $2(20 \%)$ & $3(30 \%)$ & $1(10 \%)$ \\
\hline
\end{tabular}

a framework; Delamination = veneer ceramic was damaged and the framework exposed; Catastrophic failure $=$ fracture in both the veneer

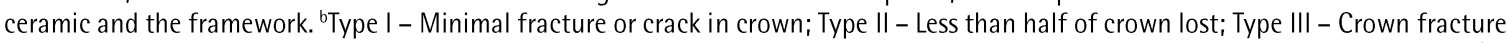
through midline with half of crown displaced or lost; Type IV - More than half of crown lost; Type V - Severe fracture of tooth and/or crown. 


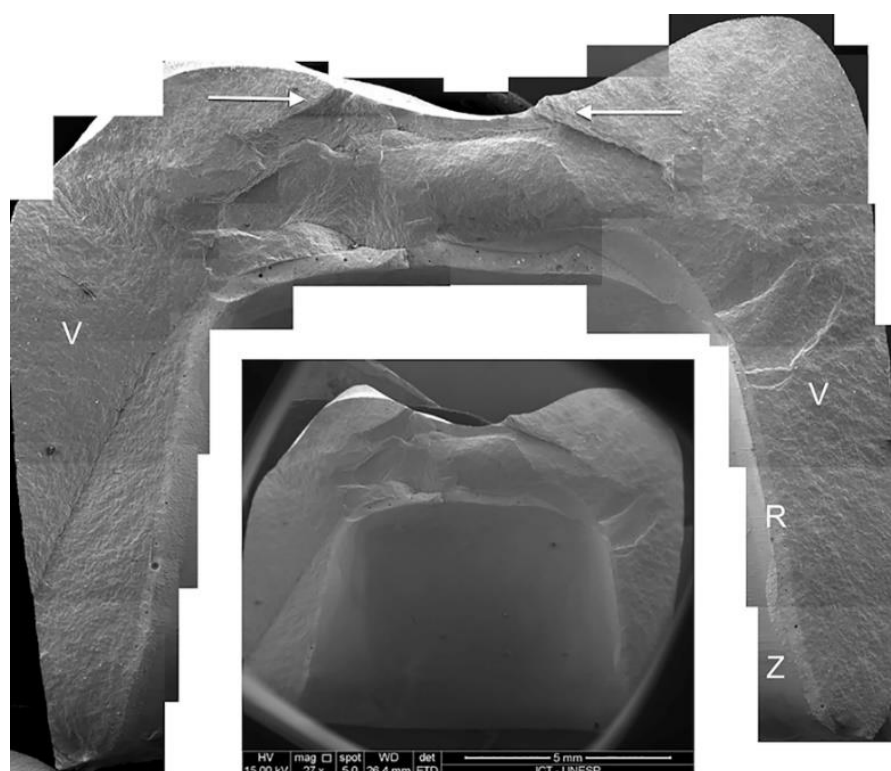

Figure 3. Higher-magnification micrographs (SEM, 150x) from the smaller micrograph (25x) of TF1 where it is possible to observe the cone cracks (arrows) that indicate failure originated on the occlusal site. The cement layer is attached to the veneer ceramic, showing complete separation from the intaglio surface. $V$, veneer ceramic; $R$, resin cement; $Z$, zirconia framework.

\section{Finite Element Analysis (FEA)}

The total deformation and von Mises criterion (equivalent tensile stress) showed coherence of the simulation, and the TF1 group showed higher concentration of tensile stress than the TF2 group. Hence, those stresses were concentrated in the center of the buccal surface. In the upper surface of the resin cement, tensile stresses induced compression stresses, which were higher for the TF1 group (487.65 MPa) than for the TF2 group (275.15 MPa) and flowed to the framework as did the tensile stress in the axial surface. On the inner surface of the veneering ceramic, the TF1 group showed a higher concentration of tensile stress at the interface between veneer ceramic and resin cement, and this could also be observed in a mesiodistal cross-section of the models. The maximum principal stresses results for the studied models are shown in Figure 4.
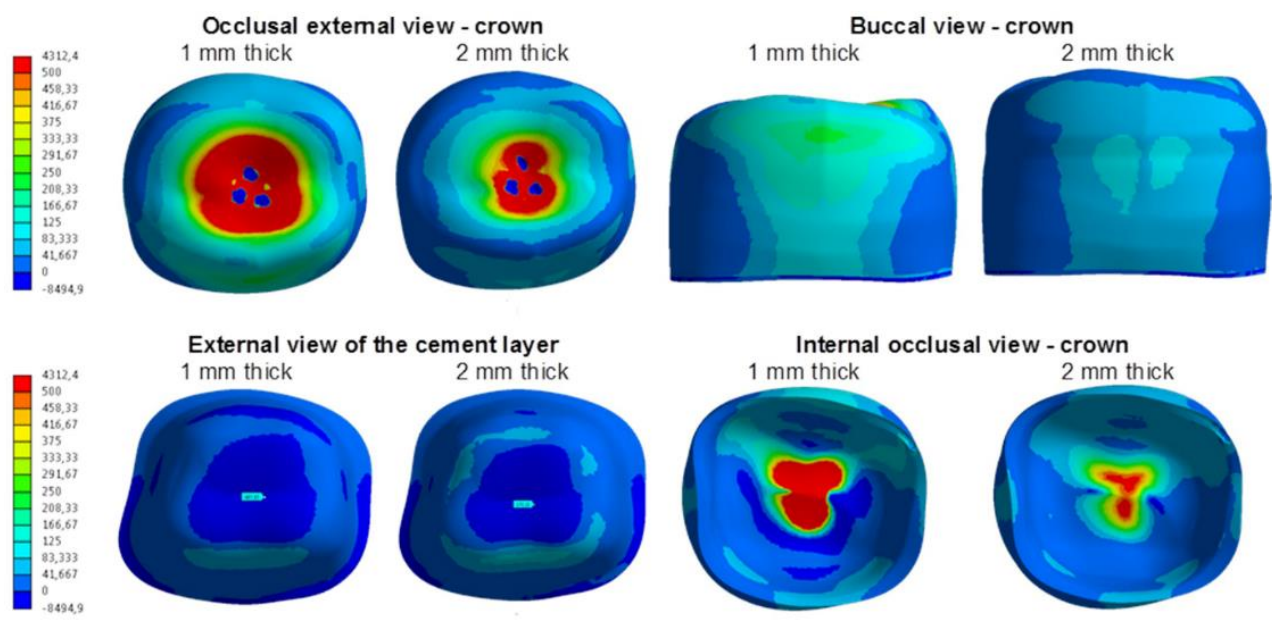

Mesiodistal cross-section of the crowns and cement layers $1 \mathrm{~mm}$ thick

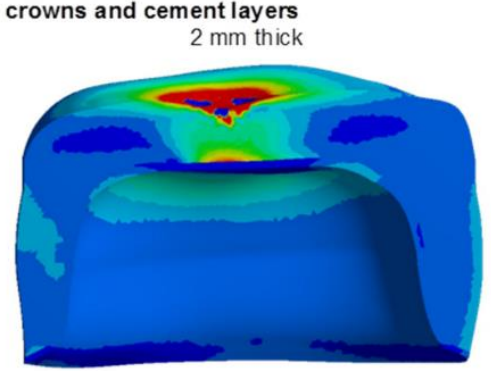

Figure 4. Maximum principal stresses results for the studied models with $10 \mathrm{kN}$ vertical load. Standardized scale 


\section{Discussion}

The manufacturing of bilayer crowns using the RLT technique have been previously investigated as a method to reduce the residual thermal stress in bilayer crowns, consequently improving their mechanical performance (15-17). Moreover, the residual thermal stress accumulation may also be affected by the veneering ceramic thickness $(18,19)$. Therefore, our study investigated the fracture resistance of bilayer crowns manufactured with veneering ceramic using the RLT technique and in two different thicknesses: 1- and 2- mm.

The disposition of the occlusal space and the degree of anatomical characterization of the restoration are factors that tend to determine the thickness of the veneering ceramic, characteristics which may vary from patient to patient. The lowest layer thickness recommended for the manufacturing of crowns utilizing the RLT technique is of $1 \mathrm{~mm}$. However, in some cases, a thicker layer is demanded to achieve a perfect anatomy and contact points (9). Based on these facts, we investigated here both 1and 2-mm veneering ceramic thickness of bilayer zirconia-based crowns. Furthermore, the fracture resistance test was chosen due to its simplicity, easy performance, as well as considered widely utilized to analyze the mechanical characteristics of oral materials (23).

The mechanical cycling was performed in all samples to simulate the masticatory loads in the oral environment and its effects on the longevity of the materials, and $2 \times 10^{6}$ cycles were applied as it has been considered as approximately four years of normal masticatory loads (24). There were no failures detected in the crowns after mechanical cycling, a find that was also confirmed in previous studies that manufactured bilayer crowns using the RLT (15-17). Schmitter et al. (16) performed thermocycling $\left(10,000\right.$ cycles, $\left.60-65^{\circ} \mathrm{C}\right)$ and mechanical cycling $\left(1.2 \times 10^{6}, 108 \mathrm{~N}\right)$ and reported that, after aging, no failures were detected in the crowns manufactured using the RLT, while 87,5\% (7 crowns) of the crowns with hand-layered veneering ceramic have failed. Another study (17) has manufactured veneering ceramic for all the crowns using CAD/CAM technology. Half of them were cemented to the framework whereas the other half were fused, and the same aging protocol utilized in Schmitter et al. (16) was performed. There was no detectable failure after aging for both scenarios investigated. Riedel et al. (15) have conducted a survival analysis and reported that no fracture was observed in the crowns with feldspathic or polymer infiltrated ceramic veneering ceramic manufactured by RLT after $2.5 \times 10^{6}$ and $3.5 \times 10^{6}$ cycles, respectively. However, any of those crowns with hand-layered veneering ceramic have remained intact after $2 \times 10^{6}$ cycles. These results may be an indicative of a more stable performance under masticatory loads on crowns manufactured using the RLT technique, a finding that may be linked to the less internal flaws detected in ceramic blocks industrially manufactured using CAD/CAM technology (2).

Our primary hypothesis tested here stating that crowns with reduced veneering ceramic thickness will present the highest fracture resistance was refused since crowns of $2 \mathrm{~mm}$ veneering ceramic thickness have presented higher fracture resistance than crowns of $1 \mathrm{~mm}$ veneering ceramic thickness. Nevertheless, our results agree with the finite element analysis (FEA) found here, which have showed that higher concentration and greater areas of tensile stress were observed in the group of the crowns having $1 \mathrm{~mm}$ occlusal thickness.

A previous study has reported that the samples with greater thickness of the veneering ceramic showed lower fracture resistance (20). However, this study have manufactured veneering ceramic using conventional technique (layering). Thus, when comparing our results with those obtained in these studies cited above one can infer that these differences may be linked to the manufacturing technique of the veneering ceramic. Presumably, there are no studies so far in the literature that have evaluated the effect of thickness on veneering ceramic fabricated by the RLT technique. Our study has utilized CAD/CAM technology to produce the ceramic blocks that supposedly tend to be more resistant to fracture due to their less internal flaws (2). Other than that, the issues related to the higher accumulation of residual thermal stress in samples with greater thickness of the veneering ceramic made by conventional techniques may have been worked out well when utilizing the RLT technique. Hence, crowns with greater thickness (veneering ceramic plus framework) have showed better stress distribution as we observed when using the FEA, thus, promoting the highest values of fracture resistance. The Weibull analysis was conducted to investigate the reliability of the groups (TF1 and TF2) having the cemented crown with 1- or 2-mm veneering ceramic thickness on occlusal. The characteristic strength of crowns with $2 \mathrm{~mm}$ veneering ceramic thickness were higher than those crowns of $1 \mathrm{~mm}$. We believe that this result can be linked to the higher tension concentration detected in the FEA for the group TF1 (with $1 \mathrm{~mm}$ veneering ceramic thickness). The Weibull modulus was similar between the two groups 
investigated in this study, indicating that the thickness tested may have not significantly affected the original imperfections (flaws).

The main failure mode was observed for the delamination of the feldspathic ceramic, exposing the zirconia framework but without compromising it. Nonetheless, it was possible to observe a higher concentration of tensile stress on the buccal surface when using the FEA, a result that might have explained the findings on the strength of the materials utilized for this study. Schmitter et al. (17) have reported that delamination was the predominant failure mode observed for the crowns with the lithium disilicate veneering ceramic and manufactured by CAD/CAM technology. These findings differ from a study that have applied conventional techniques where the most common type of failure was the chipping of the veneering ceramic (25). According to the FEA, there was a greater tensile stress at the interface between veneering ceramic/resin cement in both type of crowns, with a higher concentration at the interface of the 1-mm crowns (TF1 group). This stress concentration together with the weak adhesion between zirconia and the resin cement, may be linked to the cause of the high incidence of debonding of the cement. The fractography analysis revealed that the failure was initiated below the point of load application on the occlusal surface and with contact damage sites. While Hoop-type stresses (circumferential stress) were present, residual thermal stresses that usually promote chipping were not found in this study, a promising result that is worthy of further investigations. Also, Schmitter et al. (17) have reported the failure initiation at the occlusal surface as well as at the framework and or veneering ceramic interface.

The simplification of specimens (models) can give an idea of damage modes that are clinically relevant (21), but they do not account for complex occlusal loading, crown geometry, and other factors that play a role in the lifetime of a crown. Nevertheless, it is difficult to simulate the action of all these factors cited above, individually or in combination, in a laboratory study. Hence, caution is needed when analyzing these sorts of results. Currently, several types of ceramics are available to be worked with CAD/CAM technology, pointing out to the direction that further in vitro studies would be important to compare different sorts of materials and thickness to manufacture veneering ceramics using the RLT technique, as well as different protocols for their cementation to the framework. Moreover, we call attention here to the importance of empirical investigations on the long-term clinical performance of crowns manufactured by this technique (RLT).

\section{Conclusion}

It can be concluded here that all-ceramic crowns manufactured using the approach of $2 \mathrm{~mm}$ of veneering ceramic have promoted higher fracture resistance compared to the group with $1 \mathrm{~mm}$ veneering ceramic. Moreover, the finite element analysis (FEA) showed that the stress distribution in zirconia-based bilayer crowns was dependent on the veneer ceramic thickness.

\section{Acknowledgments}

This study was built upon a piece of a doctoral dissertation submitted to the Institute of Science and Technology, UNESP - Universidade Estadual Paulista, São Paulo, Brazil, as part of the requirements for a Ph.D. degree. Also, this study was supported by Fundação de Amparo à Pesquisa do Estado de São Paulo (FAPESP, Grants number \#2011/1218-7 and number \#2011/13085-9).

\section{Resumo}

Na RLT (Rapid Layer Technology), a cerâmica de cobertura e infraestrutura são fabricados pelo Computer-Aided Design / Computer-Aided Manufacturing (CAD / CAM) e cimentados para obter a restauração. Este estudo teve como objetivo avaliar o efeito da espessura da cerâmica de cobertura fabricada pela técnica RLT na resistência à fratura (RF) de coroas bilaminadas com infraestrutura de zircônia. Vinte infraestruturas de zircônia e vinte coroas posteriores feldspáticas com duas espessuras oclusais da cerâmica de cobertura $(1 \mathrm{~mm}=\mathrm{TF} 1 ; 2 \mathrm{~mm}=\mathrm{TF} 2)$ foram fabricadas usando o sistema CAD / CAM. Os espécimes foram cimentados em preparos de resina epóxi com cimento resinoso dual e ciclados mecanicamente $\left(200 \mathrm{~N}\right.$ e $4,5 \times 10^{5} \mathrm{~Pa}, 37^{\circ} \mathrm{C}, 2 \times 10^{6}$ ciclos, $3 \mathrm{~Hz}$ ). 0 teste de $\mathrm{RF}$ foi realizado $(10 \mathrm{kN}, 0,5 \mathrm{~mm}$ / min) e, posteriormente, os espécimes foram analisados em estereomicroscópio. Para a análise de tensão (análise de elementos finitos, FEA), uma carga de $10 \mathrm{kN}$ foi aplicada igual ao teste in vitro, e a tensão principal foi avaliada. Os dados de RF foram analisados pelo teste t de Student e análise de Weibull. A espessura mostrou forte influência na RF das coroas bilaminadas. A RF foi maior em TF2 do que no grupo TF1. 0 grupo TF2 apresentou a maior resistência caracteristica em relação ao grupo TF1. 0 tipo de falha 
predominante foi a delaminação. 0 FEA mostrou maiores concentrações de tensões abaixo do ponto de aplicação da carga, na interface cimento e cerâmica de cobertura no modelo de coroa de $1 \mathrm{~mm}$ de espessura. As coroas de bilaminadas confeccionadas com $2 \mathrm{~mm}$ de cerâmica de cobertura promoveram maior RF em comparação ao grupo com cerâmica de cobertura de $1 \mathrm{~mm}$. Além disso, a FEA mostrou que a espessura da cerâmica de cobertura tem um efeito na distribuição de tensões em coroas bilaminadas à base de zircônia. 


\section{References}

1. Mühlemann S, Benic GI, Fehmer V, Hämmerle CHF, Sailer I. Randomized controlled clinical trial of digital and conventional workflows for the fabrication of zirconia-ceramic posterior fixed partial dentures. Part II: Time efficiency of CAD-CAM versus conventional laboratory procedures. J Prosthet Dent 2019;121:252-257.

2. Li RW, Chow TW, Matinlinna JP. Ceramic dental biomaterials and CAD/CAM technology: state of art. J Prosthodont Res 2014;58:208-216.

3. Souza R, Barbosa F, Araújo G, Miyashita E, Bottino MA, Melo R, et al. Ultrathin Monolithic Zirconia Veneers: Reality or Future? Report of a Clinical Case and One-year Follow-up. Oper Dent 2018;43:3-11.

4. Felberg RV, Bassani R, Pereira GKR, Bacchi A, Silva-Sousa YT, Gomes EA, et al. Restorative Possibilities Using Zirconia Ceramics for Single Crowns. Braz Dent J. 2019;30:446-452.

5. Sailer I, Makarov NA, Thoma DS, Zwahlen M, Pjetursson BE. All-ceramic or metal-ceramic toothsupported fixed dental prostheses (FDPs)? A systematic review of the survival and complication rates. Part I: Single crowns (SCs). Dent Mater 2015;31:603-623.

6. Basso GR, Kodama AB, Pimentel AH, Kaizer MR, Della Bona A, Moraes EE, et al. Masking Colored Substrates Using Monolithic and Bilayer CAD-CAM Ceramic Structures. Oper Dent 2017:42:387-395.

7. Miura S, Kasahara $S$, Yamauchi $S$, Okuyama Y, Izumida A, Aida J, et al. Clinical evaluation of zirconia-based all-ceramic single crowns: an up to 12-year retrospective cohort study. Clin Oral Investig 2018;22:697-706.

8. Monaco C, Llukacej A, Baldissara P, Arena A, Scotti R. Zirconia-based versus metal-based single crowns veneered with overpressing ceramic for restoration of posterior endodontically treated teeth: 5year results of a randomized controlled clinical study. J Dent 2017;65:56-63.

9. Benetti P, Pelogia F, Valandro LF, Bottino MA, Della-Bona A. The effect of porcelain thickness and surface liner application on the fracture behavior of a ceramic system. Dent Mater 2011;27:948-953.

10. Anusavice KJ, Jadaan OM, Esquivel-Upshaw JF. Time-dependent fracture probability of bilayer, lithium-disilicate-based, glass-ceramic, molar crowns as a function of core/veneer thickness ratio and load orientation. Dent Mater 2013;29:1132-1138.

11. Marchionatti AME, Aurélio IL, May LG. Does veneering technique affect the flexural strength or load-to-failure of bilayer Y-TZP? A systematic review and meta-analysis. J Prosthet Dent 2018;1 19:916924.

12. Tanaka CB, Ballester RY, De Souza GM, Zhang Y, Meira JBC. Influence of residual thermal stresses on the edge chipping resistance of PFM and veneered zirconia structures: Experimental and FEA study. Dent Mater 2019;35:344-355.

13. Swain MV. Unstable cracking (chipping) of veneering porcelain on all-ceramic dental crowns and fixed partial dentures. Acta Biomater 2009;5:1668-1677.

14. Benetti P, Kelly JR, Sanchez M, Della Bona A. Influence of thermal gradients on stress state of veneered restorations. Dent Mater 2014;30:554-563.

15. Riedel $C$, Wendler $M$, Belli $R$, Petschelt $A$, Lohbauer $U$. In vitro lifetime of zirconium dioxidebased crowns veneered using Rapid Layer Technology. Eur J Oral Sci 2019;127:179-186.

16. Schmitter M, Mueller D, Rues S. In vitro chipping behaviour of all-ceramic crowns with a zirconia framework and feldspathic veneering: comparison of CAD/CAM-produced veneer with manually layered veneer. J Oral Rehabil 2013;40:519-525.

17. Schmitter $M$, Schweiger $M$, Mueller $D$, Rues $S$. Effect on in vitro fracture resistance of the technique used to attach lithium disilicate ceramic veneer to zirconia frameworks. Dent Mater 2014;30:122-130.

18. Mainjot AK, Schajer GS, Vanheusden AJ, Sadoun J. Influence of veneer thickness on residual stress profile in veneering ceramic: measurement by hole-drilling. Dent Mater 2012;28:160-167.

19. Lima JM, Souza AC, Anami LC, Bottino MA, Melo RM, Souza RO. Effects of thickness, processing technique, and cooling rate protocol on the flexural strength of a bilayer ceramic system. Dent Mater 2013;29:1063-1072.

20. Bakitian F, Seweryniak P, Papia E, Larsson C, Vult von Steyern P. Fracture strength of veneered translucent zirconium dioxide crowns with different porcelain thicknesses. Acta Biomater Odontol Scand 2017;3:74-83.

21. Kelly JR, Rungruanganunt $P$, Hunter $B$, Vailati F. Development of a clinically validated bulk failure test for ceramic crowns. J Prosthet Dent 2010;104:228-238. 
22. Burke FJ. Fracture resistance of teeth restored with dentin-bonded crowns: the effect of increased tooth preparation. Quintessence Int 1996;27:115-121.

23. Lopez-Suarez C, Tobar C, Sola-Ruiz MF, Pelaez J, Suarez MJ. Effect of thermomechanical and static loading on the load to fracture of metal-ceramic, monolithic and veneered zircônia posterior fixed partial dentures. J Prosthodont 2019;28:171-178.

24. Gjurin SZ, Özcan M, Oblak C. Zirconia ceramic fixed partial dentures after cyclic fatigue tests and clinical evaluation: a systematic review. Adv Appl Ceram 2019;118:62-69.

25. Larsson C, El Madhoun S, Wennerberg A, Von Steyern PV. Fracture strength of yttria-stabilized tetragonal zirconia polycrystals crowns with different design: an in vitro study. Clin Oral Impl Res 2012;23:820-826. 